\title{
Technogenic Seismicity on the Oil Fields of the Chechen Republic
}

\author{
$\underline{\text { Ibragim Kerimov }}^{1,2,3}$, Salavdi Badaev ${ }^{1}$ \\ ${ }^{1}$ Academy of Sciences of the Chechen Republic, 13, M. EsambaevAve., 364024, Grozny, Russia \\ ${ }^{2}$ Millionshchikov Grozny State Oil Technical University, 100, Kh. IsaevAve., 364051, Grozny, Russia \\ ${ }^{3}$ Schmidt Institute of Physics of the Earth of the Russian Academy of Sciences, 10-1, Bolshaya Gruzinskaya Str., \\ 123242, Moscow, Russia
}

doi: https://doi.org/10.21467/abstracts.93.109

\begin{abstract}
A BST RA C T
Oil continues to be one of the most important resources for the development of the economy of many countries. However, the problems of environmental pollution by oil production and oil refining products remain relevant. The problem of the negative impact of the oil and gas industry on natural components is characterized by various aspects, including air pollution due to fires at production and processing sites, flaring of associated gas, and breakthroughs of gas pipelines; the formation of technogenic deposits of hydrocarbon raw materials and associated groundwater pollution. Chechen Republic is one of the regions with high geodynamic activity and seismicity. strong earthquakes of tectonic nature were observed on its territory in historical and modern times. Along with tectonic earthquakes, seismic events related to the development of oil and gas fields were noted in the region. On the territory of the republic, oil fields that have been developed for a long time (Starogrozny, Oktyabrsky, Gudermes, etc.) are known to be confined
\end{abstract} to zones with high seismic activity.

As we know, the problem of technogenic seismicity caused by the extraction of hydrocarbons from oil fields first arose in the early 20s of the last century, with the extraction of natural gas and the injection of liquid under high pressure into the earth's crust in the mid-1960s. According to a number of researchers, the mechanism of technogenic seismicity in hydrocarbon fields mainly includes changes in the stress state of the medium, changes in pore or reservoir pressure, and displacement of liquid volumes within the medium, with characteristic features and the amount of applied forces and loads. These changes are largely interrelated, and most often, depending on the characteristics of the impact, geological structure and tectonic situation of the mountain range, it is possible to implement several mechanisms that can provide some form of manifestation of technogenic seismicity. During long-term development of hydrocarbon deposits, the equilibrium conditions in the reservoir are violated, which can cause a critical redistribution of stresses in the developed reservoir and the host rocks. The injected liquid can penetrate into cracks, lead to excessive pore-crack pressure, and can be a kind of lubricant in areas of discontinuity of the medium. These phenomena, in some cases, lead to the appearance of technogenic seismicity.

Let's consider the current geodynamics and seismicity of the territory of the three largest oil fields in the region - Starogrozny, Oktyabrsky and Gudermes. The Starogrozny oil field is located 17-20 km North-West of the center of Grozny within the Grozny ridge, which tends to the system of hills of the Sunzha ridge. Weak earthquakes in the Starogrozny district occurred very often, both before operation and during various periods of operation. Against the background of weak earthquakes in 1938 and 1963, there were significant earthquakes with $M=3.8-4.1$, excited by various factors of oil field development. On May 26, 1971, there was a strong earthquake with a focus in the area of Neftemaisk with $\mathrm{M}=4.3, \mathrm{~h}=2.8 \mathrm{~km}, \mathrm{I}_{\mathrm{o}}=7$ points, which caused the destruction of residential and industrial buildings. The 1971 earthquake occurred against the background of a sharp drop in pressure, excessive oil extraction, and the beginning of pumping water into the reservoir to intensify selection. This earthquake caused a swarm of earthquakes, called the Grozny

(C) 2020 Copyright held by the author(s). Published by AIJR Publisher in "Abstracts of The Second Eurasian RISK-2020 Conference and Symposium" April 12- 19, 2020, Tbilisi, Georgia. Jointly organized by AMIR Technical Services LLC, Georgian Technical University, Institute of Geography (Kazakhstan) and Russian Institute of Petroleum Geology and Geophysics.

AijR DOI: $10.21467 /$ abstracts. 93 
The Second Eurasian RISK-2020 Conference and Symposium

swarm. The Oktyabrsky oil field is located $8 \mathrm{~km}$ South-East of the center of Grozny and is tectonically associated with the Oktyabrsky anticline, which belongs to the Sunzha anticline zone. The geological structure of the district includes a complex of rocks from Mesozoic to anthropogenic deposits. In the arch of the Oktyabrsky anticline, upper Sarmatian deposits are exposed. Intensive selection of liquid, oil and gas in the area of the Oktyabrsky field, as well as water injection, was accompanied by a series of earthquakes, timed mainly to the time of the maximum selections and the maximum water injection on the field development schedules (1960-2010). The most intense earthquakes were observed in 1972 ( $\mathrm{K}=10.5), 1974$ ( $K=9.2-11)$, when liquid and gas samples were approaching the maximum, and in 1982 ( $K=10)$, when the volume of water injected into the Deposit increased sharply with sharply reduced production.

Thus, the analysis of the development of the upper Cretaceous Deposit allows us to establish a certain dependence of the seismicity of the subsoil on the intensity of technogenic impact on them by extracting fluid or pumping it. It is not possible to assess the impact of the intensity of the development of the Chokrak Deposit on the seismicity of the area, since there is no information about earthquakes during periods of forced fluid extraction. Gudermessky oil field is located in the Eastern part of the Terek ridge, $35 \mathrm{~km}$ East of Grozny. In orographic terms, it is represented by the Gudermes range, extending from West-Northwest to East-Southeast for $32 \mathrm{~km}$, its width is $4-4.5 \mathrm{~km}$. The field is located in a highly seismic zone. Earthquakes of various intensities have repeatedly occurred here. Here are the strongest technogenic earthquakes of 1950 and 1955 at the Gudermessky oil field - I Gudermes, March 31, H=19 km, M=4.2, I $=6-7$ points; IIGudermes, November 9, $\mathrm{H}=19 \mathrm{~km}, \mathrm{~h}_{\text {macr }}=10-60 \mathrm{~km}, \mathrm{M}=5.0, \mathrm{I}_{\mathrm{o}}=6$ points; August $23, \mathrm{H}=40 \mathrm{~km}, \mathrm{M}=4.6$, $\mathrm{I}_{\mathrm{o}}=5$ points. The earthquake occurred on the background of a sharp increase in fluid selection when developing oil deposits in the sediments of Chokrak deposits in the Eastern Gudermes. The earthquake was accompanied by fore-and aftershocks and by the nature of the mechanism has been tectonic. Subsequently, more significant earthquakes occurred in this area, for example, Kurchaloy in 2008 with $M=5.7$ and an intensity of 7-8 points at the epicenter.

The relationship between the time course of seismic activity and the dynamics of fluid extraction from the reservoir, as well as significant calculated rates of subsidence of the reservoir roof, indicate the intensive development of geodynamic processes. The relationship between seismicity and fault tectonics of oil fields can be established by analyzing structural maps of fields with earthquake epicenters, profile geological sections with earthquake hypocenters applied to them.

Conclusions. The presence of interrelations between the processes of developing mineral deposits and seismicity indicates the need to create mining enterprises in the oil fields of the region, which, along with ensuring geodynamic security, will contribute to the effective solution of scientific and experimentalmethodological problems. The organization of geodynamic monitoring in the oil fields of the region will significantly reduce the cost of eliminating the consequences of emergency situations in the future due to their predictability. The assessment of the seismic hazard of the territory based on modern methods of detailed seismic zoning and seismic micro-zoning should be performed taking into account possible technogenic earthquakes and the influence of parameters of oil and gas fields development on the seismic regime of the area.

Acknowledgements: This work was supported by Russian Foundation for Basic Research (RFBR), project number 18-45-200001 r_a. 